\title{
Olhos que dançam: breves considerações sobre o Topeng e a máscara
}

\author{
Felisberto Sabino da Costa ${ }^{1}$
}

\section{Resumo}

O artigo apresenta, de forma sucinta, alguns aspectos vivenciados no treinamento com a máscara balinesa, realizado na vila de Batuan (Bali), sob a orientação de I Made Djimat.

Palavras-chave: Topeng; Máscara; Treinamento; Corpo.

\section{Abstract}

The paper briefly presents some aspects experienced in the training performed with the Balinese mask, which was held in the village of Batuan (Bali), under the guidance of I Made Djimat.

Keywords: Topeng ; Mask ; Training ; Body.

Começa o mundo enfim pela ignorância,
e tem qualquer dos bens por natureza
a firmeza somente na inconstância.

Gregório de Mato

Esta reflexão é fruto de uma segunda experiência com o Topeng, vivenciada com I Made Djimat², em 2013, e constitui uma apreciação sintética sobre alguns temas do treinamento, finalizando com breves pontos de vista em relação à máscara. $A$ abordagem configura-se nas memórias de atravessamentos manifestadas no corpo, e a perspectiva em que se origina leva em conta as histórias pessoais que se cruzam em um certo momento. Distancia-se de uma noção de pedagogia que serve a todos. No que concerne à aprendizagem e ao ensino da máscara seria mais adequado falar e pensar em pedagogia no seu plural - pedagogias -, na medida em que, ao entrar em contato com determinado sistema pedagógico, o olhar do atuante confere certa peculiaridade a esse saber fazer. Múltiplos olhares que se debruçam sobre um mesmo objeto e, embora trilhem a mesma estrada, percebem de modo distinto.

\footnotetext{
1 Felisberto Sabino da Costa é Professor-pesquisador do Departamento de Artes Cênicas da Escola de Comunicações e Artes da Universidade de São Paulo (ECA/USP) e do Programa de Pós-Graduação em Artes Cênicas da mesma instituição.
} 


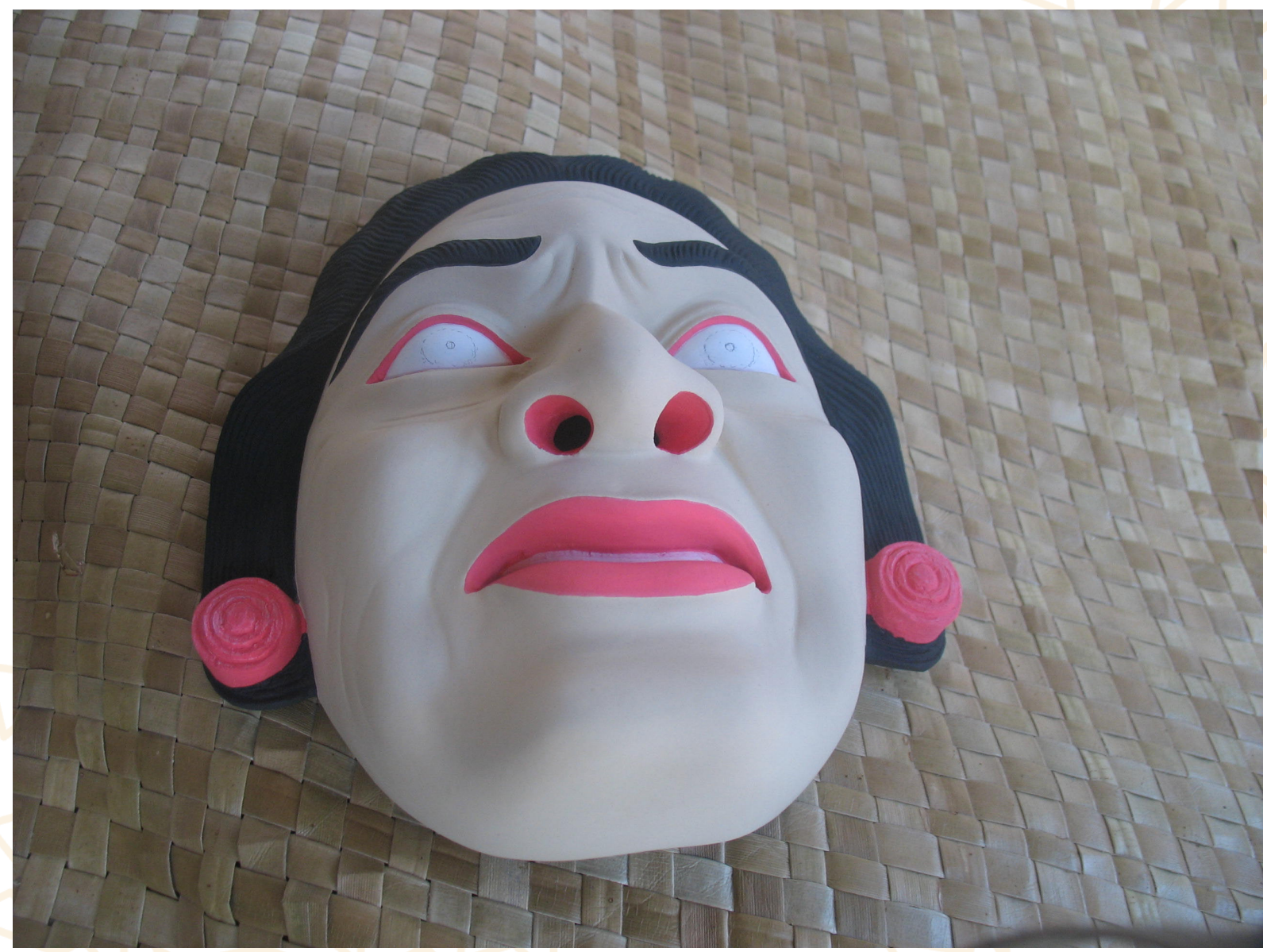

Processo de confecção da máscara da velha. Mascareiro: I Dewa P. Kebes. Batuan (Bali). Indonésia.

Nesse segundo encontro com Djimat, tive a oportunidade de experenciar a máscara que configura uma velha nominada Segara Madu. A partitura musical empregada para sua composição é a mesma que serve à máscara do velho, a contrapartida masculina. As máscaras se assemelham; porém, Semarang Made apresenta feições que lhe conferem a energia feminina. Nesse sentido, vestir ambas as máscaras foi uma espécie de experimento da polaridade masculino-feminino, ressaltando o aspecto dual que caracteriza a cultura balinesa. Conforme nos diz Jenkins,

A filosofia hindu-balinesa do ruabineda é um princípio espiritual dialético
que concebe a coexistência dos opostos, em um estado de equilíbrio
dinâmico. As trevas e a luz. O verdadeiro e o falso. O bem e o mal. Deuses
e demônios. Os balineses acreditam que todas essas forças contraditórias
existem em oposição uma à outra e que a tensão que contínua entre elas
é necessária para o funcionamento do mundo em equilíbrio. $\left(2010\right.$, p. 15) ${ }^{3}$

3 "Balinese hindu-philosophy of ruabineda, a principle of spiritual dialects that envisions the co-existence of opposites, in a state of dynamic equilibrium. Darkness and light. The true and the false. Good and evil. Gods and demons. The Balinese believe that all these contradictory forces exist in opposition to one another and that the continuing tension between them is necessary for the balanced functioning of the world". (Tradução do autor) 
Esse funcionamento (equilíbrio) do mundo não se concentra apenas no aspecto grave da vida. A coexistência referida - na qual os opostos estão em constante conflito um com o outro e, ao mesmo tempo, são inseparáveis - traz em si também o lado cômico. Assim, seguindo a trilha de Jenkins (2010, p. 35), o duo Sanggut e Delem, por exemplo, é a manifestação ruabineda em forma cômica. Embora atuem isoladamente, tanto a figura do velho quanto a da velha podem ser pensadas sobre o aspecto que envolve a constituição de um e de outro, em relação à manifestação física do ruabineda. As situações apresentadas em suas trajetórias cênicas são caracterizadas pelo deslizamento entre o sagrado e o profano, o sério e o cômico, o masculino e o feminino.

Ao iniciar cada encontro, Djimat instaura uma ambiência sagrada e invoca as forças benignas do Barong Ket. Seu poder mágico reside nos olhos e no coração, e é quem proporciona uma atmosfera protetora ao trabalho, afugentando eventos adversos. Invocar os deuses é um modo de solicitar a permissão para adentrar em outro território, sinalizando uma ambiência auspiciosa para o que será realizado. Essa descrição, possivelmente, parece algo em que o sagrado se confunde estritamente com o solene. Antes, o ambiente instaurado era prenhe da boa vida que se podia experimentar também pelo sorriso. Dito por meio de uma imagem, as folhas de gireng, colhidas na natureza, que o ator coloca ao redor dos dois lados da máscara, junto às orelhas, indica o seu estado de alegria ao atuar. No entanto, é oportuno observar que quando se diz alegria na criação, não se exclui o padecimento.

Ainda imbuído pela religião hinduísta-balinesa, Djimat observou que a dinâmica do treino é organizada em camadas, arroladas do seguinte modo: Kulit Badan (pele); Tulang Badan (osso); Darah badan merah (sangue) e Darah badan putih (sêmen, o sangue branco). É por elas que mergulhamos na dança por todo o corpo (Sahi Buta), processo que se consolida na minuciosa repetição, pois em cada refazer há um novo fazer.

No processo de aprendizagem, ter o corpo conduzido pelas mãos do mestre não significa, exatamente, imitá-lo, mas seguir o estímulo proposto, buscar o contato e o fluxo energético que possibilitam o movimento. Tocar o corpo perfaz uma conexão entre quem ensina e quem aprende e se caracteriza por sentir o outro e se deixar guiar, mas não em ser guiado. Depois de certo tempo, o corpo ganha autonomia e dança por si. Esse trabalho, que pode acontecer algumas vezes durante o treina- 
mento, estabelece uma sintonia entre os dois corpos, como se o aprendiz fosse uma máscara manipulada por seu mestre.

O treinamento leva-nos a agenciar a intensidade a fim de saber como lidar com a intensão (no) do corpo. Para tanto, é mister mergulhar em um espaço-tempo, em que o movimento se distende e vai além do corpo. Essa intensidade (e intencionalidade) do movimento se sintetiza e expande simultaneamente, tal como na poesia. Um braço que se estende de um ponto a outro no espaço dá a sensação de portar em si mesmo um tempo esgarçado, um movimento-tempo inefável que gera uma profusão de imagens no transcorrer de poucos segundos.

O rosto (do dançarino) por trás da máscara, não necessariamente, permanece impassível ou expressa as configurações plasmadas na face do objeto. Há um transitar entre o que a feição propõe (que traz como sombra a presença do mascareiro) e o corpo do ator, fronteiras cujas vizinhanças se articulam de maneira plurívoca. Entre a face e a máscara, há um território de negociação por intermédio de ações que se fazem dança. Nyoman Budi Artha ${ }^{4}$ relatou que seu rosto não se expressa como a máscara; porém, não permanece "neutro", devido ao fato de estar em sintonia com o coração, de onde parte a energia do corpo. Nos dizeres do dançarino I Nyoman Terima $^{5}$, é a expressão interna que faz mover a máscara. Portanto, mover-se é condição de existência. O lado da máscara que se mostra para o ator é o verso, este é quem toca o seu rosto e compõe a sua poesia, um jogo em que se atua nas fendas, nos espaços intervalares, em uma coexistência que busca comunhão e em uma dança engendrada por pulsões e pulsações. Mais que o movimento, a dança é a ação intensa no instante.

Durante o treino, experimenta-se o olhar do corpo e das mãos, e também outra ordem do olhar, na acepção de observar e fazer aquilo que se vê, exercitar o golpe de vista necessário à apreensão do fenômeno. Antes de vestirmos a máscara, ela já está em nosso corpo em potência, decorrente do treinamento que aporta seus princípios. Geralmente, antes de vesti-la, o dançarino olha a máscara e observa o que ela lhe proporciona naquele momento. $\mathrm{O}$ espelho serve, às vezes, para ver-se na imagem depois de colocada a máscara. Esta propõe um estado, uma energia, um jeito distinto de ser e se relacionar com o mundo, e a olhada (às vezes rápida) serve

\footnotetext{
4 BUDI ARTHA, I. N. Entrevista concedida ao autor do artigo. [21 de janeiro de 2013]. Batuan (Bali).

5 TERIMA, I.N. Entrevista concedida ao autor do artigo. [30 de janeiro de 2013]. Batuan (Bali).
} 
ao ator como parâmetro para compor a figura e também, quando necessário, para ajustar o objeto a sua face.

Na dança balinesa, os olhos também dançam e compõem uma coreografia delicada, com movimentos vigorosos ou suaves, velozes ou lentos. Em determinadas passagens, o artista semicerra os olhos ao executar um movimento ou gesto, como se revelasse o seu corpo interior, mergulhando em si mesmo para mostrar ao outro o fervor do coração, em uma espécie de corpo-oferenda, que se expõe aos diversos olhares.

A máscara é uma constelação que galvaniza espírito, corpo, objeto, figurino, música, espaço e tempo. Aquele que a veste estabelece uma relação com o espaço-tempo e interage consoante determinadas direções. O dançarino se movimenta em um espaço simbólico que se relaciona ao modo como o balinês organiza seus locais sociorreligiosos. ${ }^{6}$ Para além do lugar da apresentação, o espaço é um companheiro de jogo, uma ambiência que habita o corpo ao mesmo tempo em que é habitado. Ao vestir a máscara, o objeto acolhe e toca o corpo com intensidade, estabelece o contato da matéria e energia que pressiona a face, estando em jogo os elementos contraditórios da existência.

No que concerne ao seu jogo em cena, há diversos aspectos evidenciados por mascareiros quanto às qualidades que tal objeto deve portar em si para ser considerado bom. Acredito que uma máscara seja boa quando promove a experiência da diferença: é ambivalente e, ao invés de propor, convida a um mergulho conjunto, nutrido pela ignorância. É sob essa última perspectiva que podemos pensar as máscaras utilizadas em nosso treinamento. Tal como na poesia de Drummond (2013), uma máscara "que fale como dois olhos" quando tece a sua canção.

Entre outras possibilidades, poderíamos associar a experiência do mascaramento a determinados aspectos do khôra. Platão nos diz que tal entidade (receptáculo) invisível e incerta recebe todas as coisas e partilha misteriosamente do inteligível, e é, sobretudo, incompreensível. Esse terceiro gênero, que é sempre o do espaço, é visto como em um sonho (1986). Portanto, advém-se a possibilidade de um fluxo sem fim de imagens geradas nesse entre-lugar (ou região), no qual se busca a potencialidade do simulacro.

$6 \mathrm{Na}$ arquitetura balinesa, o equilíbrio entre bhuana agung (macrocosmo/universo) e bhuana alit (microcosmo, humano, ambiente), Utama (área sagrada); mandala (neutral área) e nista (área para os aspectos sujos), real ou abstrato, é considerado fundamental. 
Por fim, apropriando-se dos dizeres de Viveiros de Castro (2002) quanto ao perspectivismo ameríndio, observa-se que, nesse mundo povoado de muitas espécies de seres, a forma corporal de cada espécie é uma roupa ou invólucro (máscara), ocultando uma forma interna humana. Logo, a sua firmeza reside na inconstância.

\section{Referências bibliográficas}

ANDRADE, Carlos Drummond de. Canção amiga. Disponível em: http://www.algumapoesia. com.br/drummond/drummond16.htm. Acesso em: 7 jun. 2013.

JENKINS, R. Rua Bineda in Bali. Counterfeit justice in the Trial of Nyoman Gunarsa. Jogjakarta (Indonesia): ISI, 2010.

PLATÃO. Diálogos, vol. XI. Timeu, Crítias, o Segundo Alcebíades, Hípias Menor. Trad. Carlos Alberto Nunes. Belém: Editora da UFPA, 1986.

VIVEIROS DE CASTRO, E. A inconstância da alma selvagem. São Paulo: Cosac \& Naify, 2002. 